PBO at W24; results of prespecified sensitivity and subgroup analyses were consistent. GUS safety in TNF-IR PsA pts through W24 is consistent with the favorable GUS safety profile in psoriasis and biologic-naïve PsA pts. ${ }^{3}$ REFERENCES:

[1] Deodhar A. Lancet 2018;391: 2213-24.

[2] Mease PJ. Lancet 2020;395: 1126-36.

[3] Guselkumab Prescribing Information. Janssen Biotech, Inc.

Disclosure of Interests: Laura C Coates Consultant of: AbbVie, Amgen, Biogen, BMS, Boehringer Ingelehim, Celgene, Domain, Eli Lilly, Gilead, Janssen, Medac, Novartis, Pfizer and UCB, Grant/research support from: AbbVie, Amgen, Celgene, Eli Lilly, Gilead, Novartis, Pfizer, Laure Gossec Consultant of: AbbVie, Amgen, BMS, Biogen, Celgene, Eli Lilly, Gilead, Janssen, Novartis, Pfizer, Samsung Bioepis, Sanofi-Aventis, UCB, Grant/research support from: Amgen, Eli Lilly, Galapagos, Janssen, Pfizer, Sandoz, Sanofi, Elke Theander Shareholder of: Johnson \& Johnson, Employee of: Janssen Scientific Affairs, LLC, Paul Bergmans Shareholder of: Johnson \& Johnson, Employee of: Janssen, Marlies Neuhold Shareholder of: Johnson \& Johnson, Employee of: Janssen Scientific Affairs, LLC, Chetan Karyekar Shareholder of: Johnson \& Johnson, Employee of: Janssen Global Services, LLC, May Shawi Shareholder of: Johnson \& Johnson, Employee of: Janssen Global Services, LLC, Wim Noel Shareholder of: Johnson \& Johnson, Employee of: Janssen Scientific Affairs, LLC, Georg Schett: None declared, lain Mclnnes Consultant of: AbbVie, Bristol-Myers Squibb, Celgene, Eli Lilly, Gilead, Janssen, Novartis, Pfizer, and UCB, Grant/research support from: Bristol-Myers Squibb, Celgene, Eli Lilly, Janssen, Novartis, and UCB

Figure. ACR 20 Response through Week 24 of COSMOS.

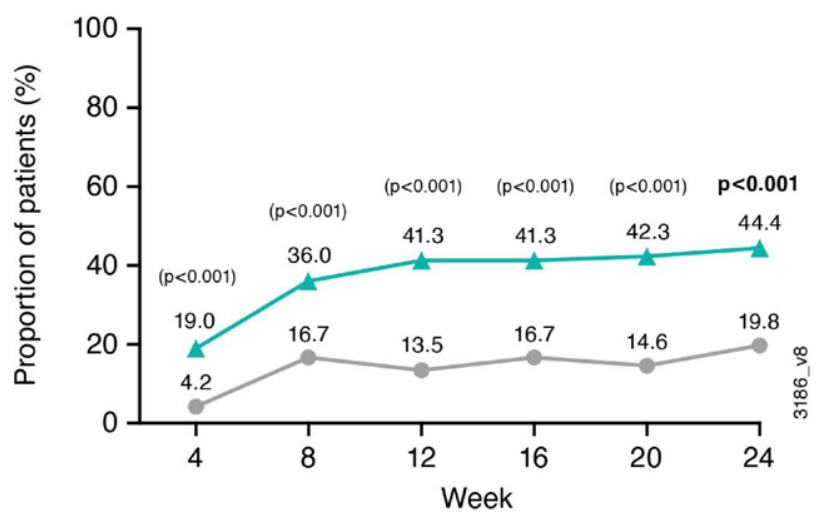

$$
\longrightarrow \text { GUS } 100 \mathrm{mg} \text { Q8W }(\mathrm{n}=189) \longrightarrow \text { PBO }(\mathrm{n}=96)
$$

Bolded $p$ values are adjusted for multiplicity of testing; $p$ values shown in parentheses are not adjusted for multiplicity of testing

DOI: 10.1136/annrheumdis-2021-eular.42

\section{OP0231 DIFFERENCES IN REAL-WORLD PATIENT CHARACTERISTICS OF 8921 PSORIASIS PATIENTS WITH AND WITHOUT COMORBID PSORIATIC ARTHRITIS USING THE UK BADBIR DATABASE}

W. Tillett ${ }^{1}$, A. Ogdie ${ }^{2}$, P. Gorecki ${ }^{3}$, A. Passey ${ }^{4} .{ }^{1}$ Royal National Hospital for Rheumatic Diseases, Rheumatology, Bath, United Kingdom; ${ }^{2}$ University of Pennsylvania, Perelman School of Medicine, Philadelphia, United States of America; ${ }^{3}$ Janssen, Medical Affairs, High Wycombe, United Kingdom; ${ }^{4}$ Janssen Real World Evidence, HEMAR EMEA, High Wycombe, United Kingdom

Background: Psoriatic arthritis (PsA) is a chronic inflammatory arthritis associated with psoriasis ( $\mathrm{PsO}$ ) and multiple comorbidities. ${ }^{1}$ Approximately one-third of $\mathrm{PsO}$ patients develop PsA during the course of their disease. ${ }^{2}$ As patient cohorts included in randomised clinical trials are not necessarily representative of the real world, registry data can complement any information gained on patient characteristics and disease outcomes. ${ }^{3}$ The British Association of Dermatologists Biologic and Immunomodulators Register (BADBIR) is one such registry for patients with plaque $\mathrm{PsO}$, with $\mathrm{PsA}$ being one of the recorded comorbidities at time of patient enrolment into the database.

Objectives: The primary objective of this study was to evaluate baseline characteristics and comorbidities in PsO patients with and without a PsA diagnosis using the BADBIR database. The hypothesis was that patients with both diseases show a higher likelihood of being diagnosed with additional comorbid conditions vs. PsO alone.

Methods: This was a retrospective observational study using two cohorts of BADBIR data (i.e. adult PsO patients either receiving ustekinumab [UST] as their biologic treatment or receiving conventional systemic anti-psoriatic medication [conventional systemic]). Comparisons were made between PsA and PsO alone in each cohort at baseline, additionally stratifying by biologic experience in the UST treatment group. Baseline characteristics of interest were evaluated, including body mass index, smoking and employment status, as well as comorbidities (i.e. diabetes, hypertension, myocardial infarction and depression). Effect sizes and $95 \%$ confidence intervals were generated via matching with a two-sided Fisher's exact test.

Results: Cohort patient counts were as follows: 2697 UST treated without PsA 590 UST treated with PsA; 5105 conventional systemic without PsA; 529 conventional systemic with PsA. PsO patients with a PsA diagnosis had a higher prevalence of diabetes, obesity and hypertension across both conventional systemic and UST cohorts vs. PsO alone (Table 1). Similarly, inability to work was notably higher in $\mathrm{PsO}$ patients with $\mathrm{PsA}$ vs. $\mathrm{PsO}$ alone (Figure 1). Patients with $\mathrm{PsO}$ and comorbid PSA who were receiving UST were more likely to have a diagnosis of depression than those receiving conventional systemic treatment (Table 1).

Table 1. Prevalence odds ratio of baseline characteristics of patients with PsO treated with either UST or a conventional systemic agent.

\begin{tabular}{lccc}
\hline Baseline variable & Treatment cohort & Odds ratio & 95\% Cl \\
\hline Ability to work & UST & 0.27 & $0.21-0.35$ \\
& Conventional systemic & 0.49 & $0.37-0.65$ \\
Smoking & UST & 0.94 & $0.76-1.17$ \\
& Conventional systemic & 0.72 & $0.58-0.89$ \\
Depression & UST & 1.54 & $1.25-1.88$ \\
& Conventional systemic & 1.14 & $0.91-1.42$ \\
Obesity* & UST & 1.34 & $1.11-1.62$ \\
Diabetes & Conventional systemic & 1.21 & $1.01-1.46$ \\
& UST & 1.45 & $1.10-1.89$ \\
Hypertension & Conventional systemic & 1.51 & $1.11-2.04$ \\
\multirow{2}{*}{ Myocardial infarction } & UST & 1.54 & $1.26-1.87$ \\
& Conventional systemic & 1.30 & $1.03-1.62$ \\
& UST & 1.67 & $0.98-2.76$ \\
& Conventional systemic & 1.17 & $0.56-2.21$ \\
\hline
\end{tabular}

Odds ratios and $95 \% \mathrm{Cls}$ are shown for the prevalence of each patient baseline characteristic in the $\mathrm{PsO}$ with comorbid PsA group vs. the prevalence in the $\mathrm{PsO}$ group. ${ }^{*}$ Obesity is define as a $\mathrm{BMI} \geq 30 \mathrm{~kg} / \mathrm{m}^{2}$. BMI, body mass index; $\mathrm{Cl}$, confidence interval; PsA, psoriatic arthritis; PsO, psoriasis; UST, ustekinumab.

Conclusion: These results indicate that $\mathrm{PsO}$ patients with PsA had a higher prevalence of obesity, diabetes, hypertension and inability to work vs. PsO alone. Depression also seems to be more prevalent in $\mathrm{PsO}$ patients with comorbid PsA receiving biologic treatment vs. those receiving conventional systemics. These results potentially indicate a higher inflammatory and quality-of-life burden in $\mathrm{PsO}$ patients with a PsA diagnosis, highlighting the need for adequate patient assessment and follow-up to ensure a best possible holistic patient management approach.

\section{REFERENCES:}

[1] Shah et al. RMD Open 2017;3:e000588

[2] Coates et al. Lancet 2015;386:2489-98

[3] Mason et al. JAMA Dermatol 2018;154:581-8

Disclosure of Interests: William Tillett Speakers bureau: AbbVie, Amgen, Celgene, Eli Lilly, Janssen, Novartis, Pfizer and UCB, Consultant of: AbbVie, Amgen Celgene, Eli Lilly, Janssen, Novartis, MSD, Pfizer and UCB, Grant/research support from: AbbVie, Celgene, Eli Lilly, Janssen and UCB, Alexis Ogdie Consultant of: AbbVie, Amgen, Bristol-Myers Squibb, Celgene, Corrona, Janssen, Eli Lilly, Novartis and Pfizer, Grant/research support from: Pfizer to Penn, Novartis to Penn, Amgen to Forward/NDB, Patricia Gorecki Employee of: Janssen-Cilag Ltd, Alun Passey Employee of: Janssen-Cilag Ltd

Figure 1: Employment status of patients with $\mathrm{PsO}$ by presence of comorbid PsA and treatment type 100

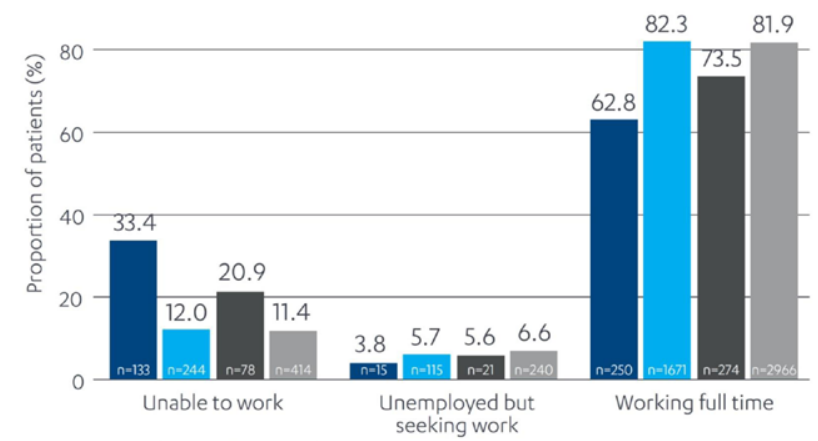

PsA, psoriatic arthritis; PsO, psoriasis.

DOI: 10.1136/annrheumdis-2021-eular.1018 